\title{
The immune response after hypoxia-ischemia in a mouse model of preterm brain injury
}

\author{
Anna-Maj Albertsson ${ }^{1}$, Dan Bi ${ }^{1,2}$, Luqi Duan ${ }^{1,2}$, Xiaoli Zhang ${ }^{1,2}$, Jianmei W Leavenworth ${ }^{3,4}$, Lili Qiao ${ }^{1,5}$, Changlian Zhu ${ }^{2,6}$, \\ Susanna Cardell ${ }^{7}$, Harvey Cantor ${ }^{3,4}$, Henrik Hagberg ${ }^{1,8,9}$, Carina Mallard ${ }^{1}$ and Xiaoyang Wang ${ }^{1,2^{*}}$
}

\begin{abstract}
Background: Preterm brain injury consists primarily of periventricular leukomalacia accompanied by elements of gray-matter injury, and these injuries are associated with cerebral palsy and cognitive impairments. Inflammation is believed to be an important contributing factor to these injuries. The aim of this study was to examine the immune response in a postnatal day (PND) 5 mouse model of preterm brain injury induced by hypoxia-ischemia (HI) that is characterized by focal white and gray-matter injury.
\end{abstract}

Methods: $\mathrm{C} 57 \mathrm{BI} / 6$ mice at PND 5 were subjected to unilateral $\mathrm{HI}$ induced by left carotid artery ligation and subsequent exposure to $10 \% \mathrm{O}_{2}$ for 50 minutes, 70 minutes, or 80 minutes. At seven days post-Hl, the white/gray-matter injury was examined. The immune responses in the brain after $\mathrm{HI}$ were examined at different time points after $\mathrm{HI}$ using RT-PCR and immunohistochemical staining.

Results: $\mathrm{HI}$ for 70 minutes in PND 5 mice induced local white-matter injury with focal cortical injury and hippocampal atrophy, features that are similar to those seen in preterm brain injury in human infants. HI for 50 minutes resulted in a small percentage of animals being injured, and $\mathrm{HI}$ for 80 minutes produced extensive infarction in multiple brain areas. Various immune responses, including changes in transcription factors and cytokines that are associated with a T-helper (Th)1/Th17-type response, an increased number of CD4+ T-cells, and elevated levels of triggering receptor expressed on myeloid cells 2 (TREM-2) and its adaptor protein DNAX activation protein of $12 \mathrm{kDa}$ (DAP12) were observed using the $\mathrm{HI} 70$ minute preterm brain injury model.

Conclusions: We have established a reproducible model of HI in PND 5 mice that produces consistent local white/ gray-matter brain damage that is relevant to preterm brain injury in human infants. This model provides a useful tool for studying preterm brain injury. Both innate and adaptive immune responses are observed after $\mathrm{HI}$, and these show a strong pro-inflammatory Th1/Th17-type bias. Such findings provide a critical foundation for future studies on the mechanism of preterm brain injury and suggest that blocking the Th1/Th17-type immune response might provide neuroprotection after preterm brain injury.

Keywords: Brain injury, Preterm, Hypoxia-ischemia, Immune response

\section{Background}

Prematurity is associated with an elevated risk of suffering from brain injuries, and these brain injuries are associated with impaired quality of life due to disorders such as cerebral palsy and behavioral, social, attentional, and cognitive deficits. The most common form of brain injury

\footnotetext{
* Correspondence: xiaoyang.wang@fysiologi.gu.se

${ }^{1}$ Perinatal Center, Department of Neuroscience and Physiology, Sahlgrenska Academy, University of Gothenburg, Box 432, SE-405 30 Gothenburg, Sweden ${ }^{2}$ Department of Pediatrics, The Third Affiliated Hospital of Zhengzhou University, Zhengzhou, China

Full list of author information is available at the end of the article
}

in preterm infants is generally thought to consist primarily of periventricular leukomalacia (PVL), a specific form of cerebral white-matter injury that is often accompanied by elements of gray-matter injury [1-3]. PVL can be either cystic necrotic or non-cystic. The cystic necrotic form is associated with the loss of all cellular elements, but the non-cystic lesions are more diffuse and cell-specific. The diffuse non-cystic lesions are the most common form of injury seen in preterm infants at present, and these primarily affect premyelinating oligodendrocytes (preOLs)
C Biomed Central

(C) 2014 Albertsson et al.; licensee BioMed Central Ltd. This is an Open Access article distributed under the terms of the Creative Commons Attribution License (http://creativecommons.org/licenses/by/4.0), which permits unrestricted use, distribution, and reproduction in any medium, provided the original work is properly credited. The Creative Commons Public Domain Dedication waiver (http://creativecommons.org/publicdomain/zero/1.0/) applies to the data made available in this article, unless otherwise stated. 
leading to either loss of these cells or their inability to differentiate into mature oligodendrocytes, which results in cerebral hypomyelination [4-6].

Hypotensive episodes and hypoxic events, inflammation and infection [7-9], and tissue hypoxia arising from inflammation/infection are the major initiating factors of preterm brain injury. The ischemia-reperfusion injury process has been confirmed by the presence of infarctions in the arterial end and border zones of the periventricular white matter $[10,11]$ and by the observation of pressurepassive circulation without autoregulatory function in newborn infants [12]. The most commonly used method for studying hypoxia-ischemia (HI)-induced brain damage in the neonatal brain is a rodent $\mathrm{HI}$ model referred to as the Vannucci model [13]. This model is very well characterized for mice and rats between postnatal day (PND) 7 and PND 10 [14-21], and adaptations in younger rodent pups including PND 3 to 6 rats [22] and PND 6 to 7 mice $[23,24]$ have also been developed. The periventricular white matter in humans is highly susceptible to HI at gestational weeks 24 to 32 due to its high proportion of preOLs, and it is known that the number of preOLs is highest at PND 2 to 5 in rodents and that this number quickly declines after this developmental stage [25]. By PND 6-7, extensive oligodendrocyte (OL) maturation occurs in rodents and this coincides with the onset of early myelination [26]. Thus, white-matter vulnerability in the rodent at PND 2 to 5 would correspond to that in preterm human infants.

HI-induced injury to the immature brain has been found to induce the expression of various genes related to immune responses and inflammation, including macrophage and microglia-related genes, T-lymphocyte-related genes, and cytokines [27]. In addition, inflammatory mediators have been suggested to contribute to injury after $\mathrm{HI}$ in the immature brain [28] at a stage corresponding to human term and near-term infants. The immune system develops rapidly immediately after birth. For example, mice are not able to produce detectable levels of humoral antibodies in response to antigen until after one week of age, and the antigen-presenting dendritic cells do not reach normal levels as it is in adult rodent until one week after birth [29]. This indicates that the inflammatory response is likely to be very different during the first days after birth compared to one week later, and the differences are even more pronounced compared to older rodents [29]. However, the inflammatory and immune responses after $\mathrm{HI}$ brain injury in mice younger than PND 7 have not been characterized. The first aim of this study was to use the Vannucci model to find the duration of hypoxia that causes focal white/ gray-matter injury in PND 5 mice, a developmental age in mice that corresponds to the preterm human infant. The second aim was to characterize the immune/inflammatory response after $\mathrm{HI}$ in this preterm injury model.

\section{Methods}

Animals

Pregnant C57BL/6 J mice were purchased from Charles River Laboratories (Sulzfeld, Germany) and these gave birth in the animal facility at the University of Gothenburg (Experimental Biomedicine, University of Gothenburg). The day of birth was defined as PND 1. Mice were housed with a 12-hour light/dark cycle, and free access to a standard laboratory chow diet (B\&K, Solna, Sweden) and drinking water was provided. All animal experiments were approved by the Animal Ethical Committee of Gothenburg (Number 51/2012, 5/2013).

\section{Hypoxia-ischemia procedure}

At PND 5, mice of both sexes were subjected to HI insult according to a method described previously with some modifications [13]. Briefly, mice were anesthetized with isoflurane $(5.0 \%$ for induction and 1.5 to $3.0 \%$ for maintenance) in a 1:1 mixture of nitrous oxide and oxygen. The left common carotid artery was ligated, and the mice were returned to their cage and allowed to recover for one hour. The mice were then placed in an incubator perfused with a humidified gas mixture $(10 \pm 0.01 \%$ oxygen in nitrogen) at $36^{\circ} \mathrm{C}$ for 50 minutes, 70 minutes, or 80 minutes. After $\mathrm{HI}$, the pups were returned to their dam until being killed. The combination of artery ligation and hypoxia resulted in injury only in the hemisphere ipsilateral to the artery ligation (the left hemisphere), while no injury was produced in the contralateral hemisphere (the right hemisphere). PND 9 mice were subjected to hypoxia for 50 minutes to produce a comparable degree of injury in the hippocampus as seen after 70 minutes HI in the PND 5 mice [30].

\section{Assessment of brain damage}

Mice were deeply anesthetized and perfused intracardially with saline and 5\% buffered formaldehyde (Histofix; Histolab Products AB, Gothenburg, Sweden). The brains were dissected, paraffin-embedded, and cut into 10- $\mu \mathrm{m}$ coronal sections throughout the whole brain. Immunohistochemical staining for microtubule-associated protein 2 (MAP-2) and myelin basic protein (MBP) was performed on every 50th section.

The extent of white- and gray-matter injury was analyzed by quantitative measurements of the injury area (at $4 \times$ magnification) using Micro Image version 4.0 (Micro-macro AB, Gothenburg, Sweden). The MAP-2positive or MBP-positive area (remaining tissue) was measured in each hemisphere as previously described $[31,32]$, and total tissue loss was calculated as:

(Contralateral hemisphere-ipsilateral hemisphere) / Contralateral hemisphere) $\times 100 \%$ 
Coronal sections at the hippocampal level were used for all other staining. Thionin/acid fuchsin staining was performed as described previously [33]. Briefly, the sections were dipped in $1 \%$ thionin/toluidin solution, dipped into acid fuchsin solution, and dehydrated in a gradient of ethanol before mounting.

\section{Immunohistochemical staining}

After antigen recovery and blocking, the following primary antibodies were used: mouse anti-MAP-2 (clone HM-2, Sigma-Aldrich, Stockholm, Sweden), mouse antiMBP (SMI94, Covance, NJ, USA), goat anti-triggering receptor expressed on myeloid cells-2 (TREM-2, clone G-18, Santa Cruz Biotechnology, Santa Cruz, CA, USA), rabbit anti-ionized calcium binding-adapter molecule 1 (Iba-1, Wako Chemicals, Richmond, VA, USA), and mouse anti-cluster of differentiation 4 (CD4, Vector Laboratories, Burlingame, CA, USA). After incubation with the appropriate biotinylated secondary antibody (Vector Laboratories, Burlingame, CA, USA), visualization was performed using Vectastain ABC Elite with 3,3'-diaminobenzidine (DAB) enhanced with ammonium nickel sulfate, beta-D glucose, ammonium chloride, and beta-glucose oxidase (all from Sigma-Aldrich, Stockholm, Sweden).

For fluorescent triple staining, the sections were incubated with goat anti-TREM-2, mouse anti-DNAX activating protein 12 antibody (DAP12, clone B-2, Santa Cruz Biotechnology, Santa Cruz, CA, USA) and rabbit anti-Iba-1. The sections were then incubated with the appropriate Alexa Fluor 594 donkey-anti-rabbit or Alexa Fluor 488 donkey-anti-mouse (Molecular Probes, Leiden, Netherlands) secondary antibody in PBS, and a coverslip was mounted using ProLong Gold antifade reagent with 4,6-diamidino-2-phenylindole (DAPI) (Life Technologies, Carlsbad, CA, USA).

\section{RT-PCR}

Changes in cytokine gene expression in the brain at 6 hours, 24 hours, or 7 days after HI in PND 5 and control mice were analyzed by RT-PCR. After a brief intracardial perfusion with saline, the brains were rapidly dissected, divided into ipsilateral and contralateral hemispheres, snap frozen, and stored at $-80^{\circ} \mathrm{C}$ until use.

The brain tissue was homogenized with Qiazol lysis reagent homogenizer (Qiagen, Sollentuna, Sweden), and total RNA was extracted using the RNeasy Lipid Tissue Mini Kit (Qiagen, Sollentuna, Sweden). RNA was measured with a spectrophotometer at $260 \mathrm{~nm}$ absorbance. cDNA was synthesized using a QuantiTect Reverse Transcription Kit (Qiagen, Sollentuna, Sweden) following the manufacturer's instructions, and each sample was run in duplicate. The following primers were used: RARrelated orphan receptor gamma (ROR $\gamma \mathrm{t}, \mathrm{QT}$ 00197722), T-bet (QT00129822), GATA binding protein 3 (GATA3,
QT00170828), forkhead box P3 (Foxp3, QT00138369), IL-4 (QT00160678), IL-5 (QT00099715), IL-6 (QT00098875), IL-10 (QT00106169), IL-12a (p35) (QT01048334), IL-13 (QT02423449), IL-17 $\alpha$ (QT00103278), IL-21 (QT01758036), IL-22 (QT00128324), IL-23a (QT01663613), transforming growth factor beta (TGF- $\beta$, QT01038821), IFN- $\gamma$ (QT00145250), B- and T-lymphocyte attenuator (BTLA, QT0 0117635), CXCR5 (QT00253449), CXCL13 (QT00107919), inducible T-cell co-stimulator (ICOS, QT02253552), and 18S ribosomal RNA (QT01036875) (all from Qiagen, Sollentuna, Sweden). Melting curve analysis was performed to ensure that only one PCR product had been produced. A standard curve was generated for quantification and for estimating amplification efficiency using increasing concentrations of cDNA, and the amplification transcripts were quantified with the relative standard curve and normalized to the $18 \mathrm{~S}$ ribosomal RNA reference gene.

\section{Statistics}

The Statistical Package for the Social Sciences (SPSS Inc., Chicago, IL, USA) v19.0 software package was used for all analyses. Comparisons between groups were performed by Student's $t$-test, and data with unequal variance were compared with the Mann-Whitney $U$-test. Analysis of variance followed by the LSD post-hoc test was used for comparison of data from more than two groups. $P<0.05$ was considered statistically significant.

\section{Results}

\section{White/gray-matter injury after $\mathrm{HI}$ in PND 5 mice}

To determine the duration of hypoxia in PND 5 mice that produces mild and focal white/gray-matter injury, we tested hypoxia durations of 50 minutes, 70 minutes, and 80 minutes in combination with left carotid artery ligation using the Vannucci model. Mice were killed three or seven days after $\mathrm{HI}$ to evaluate the extent of brain injury. All pups tolerated HI well and none of the pups died during or soon after the HI insult. Thionin/ acid fuchsin staining showed that after 50 minutes of hypoxia only $3 / 12(25 \%)$ of the mice had suffered visible brain injury (Table 1). The injury was mostly found in the hippocampus and was characterized by loss of neurons in the CA1 to CA3 areas in the cerebral hemisphere ipsilateral to the carotid ligation (Table 1, Figure $1 \mathrm{~B}$, arrows in Figure $2 \mathrm{D}$ and $2 \mathrm{H}$ ). No injury was found in the contralateral hemisphere (Figure $1 \mathrm{~A}$ and Figure $2 \mathrm{C}$ and $2 \mathrm{E})$. Only $2 / 12$ (17\%) of the mice displayed mild local white-matter tissue disruption in the ipsilateral hemisphere (Figure 2D and 2G) in comparison to the contralateral hemisphere (Figure 1A and Figure 2C and $2 \mathrm{~F}$ ).

When the duration of hypoxia was extended to 70 minutes, 13/14 (93\%) of the mice were injured (Table 1). The 
Table 1 Brain injury with different durations of hypoxia-ischemia (HI) in postnatal day (PND) 5 mice

\begin{tabular}{lllll}
\hline Hypoxia time & Percent of injured mice & CX injury & Hipp. injury & Subcortical WM injury \\
\hline 50 minutes & $25 \%$ & No & Loss of granular cells in the CA areas & Localized and diffuse \\
70 minutes & $93 \%$ & selective neuronal injury & Tissue structure disruptions & WM diffuse injury and tissue \\
& & & & structure disruptions \\
80 minutes & $88 \%$ & Infarction & Infarction & Infarction \\
\hline
\end{tabular}

Abbreviations: $C A$ cornu ammonis, $C X$ cortex $H I$ hypoxia-ischemia, Hipp hippocampus, PND postnatal day, WM white matter.

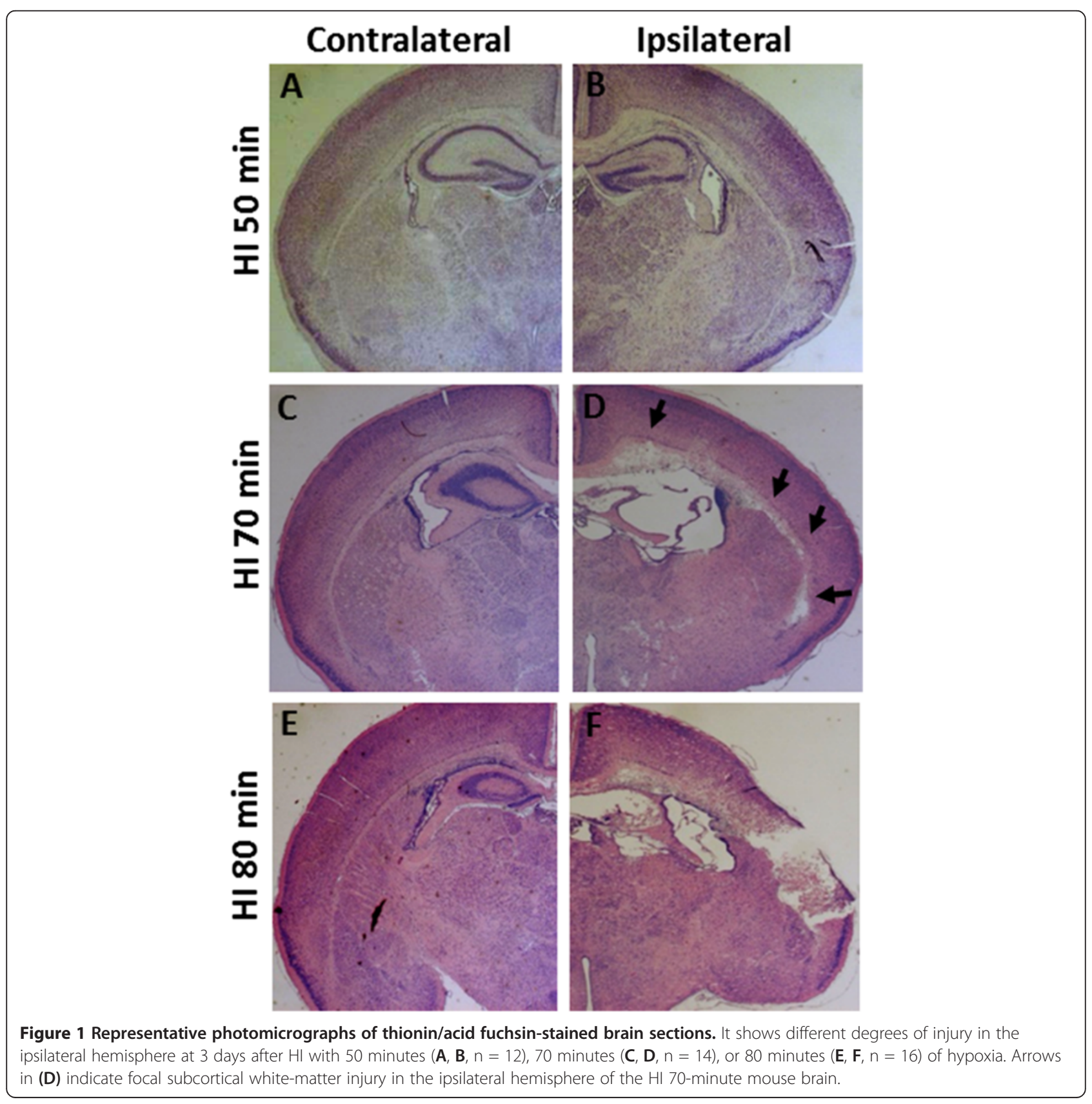



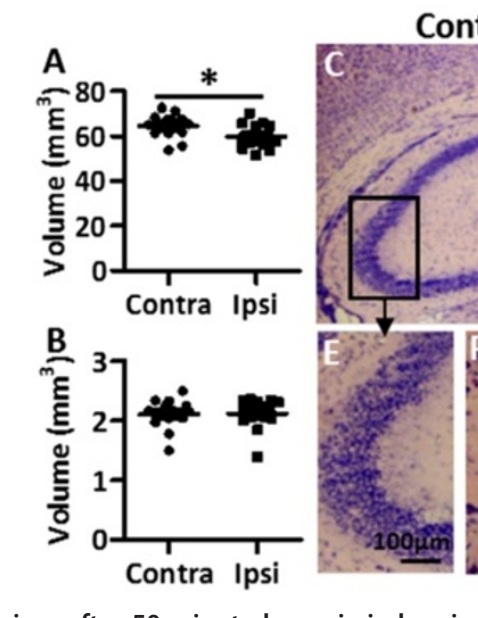

\section{Contralateral}

Figure 2 Brain injury after 50-minute hypoxia-ischemia (HI) insult. Dot graphs show the volume difference between the ipsilateral and contralateral hemispheres in gray matter $\mathbf{( A )}$ and white matter $\mathbf{( B )}$ at 7 days after 50-minute HI in PND 5 mice $(n=16)$. Abbreviations: Contra: contralateral hemisphere; Ipsi: ipsilateral hemisphere. ${ }^{*} P<0.05$ by Student's unpaired $t$-test. Data are presented as mean \pm SEM. (C-H) Representative photomicrographs of thionin/acid fuchsin-stained sections show diffuse injury in the subcortical white matter area (D and G) and focal granular layer loss in the hippocampus CA3 area (D and $\mathbf{H}$ ) that is only observed in the ipsilateral hemisphere and not in the contralateral hemisphere (C, $\mathbf{E}$, and $\mathbf{F}$ ) at 3 days after HI in PND 5 mice. Arrows in (D) indicate focal injury in the CA1 granular layer of the hippocampus in the ipsilateral hemisphere.

injury was characterized by hippocampal injury in combination with focal white-matter injury (arrows in Figure 1D, and Figure 3D) as well as small areas of focal cortical injury in the ipsilateral hemisphere (star and arrows in Figure 3E). Only $1 / 14(7.1 \%)$ of the mice showed cortical infarction. Notably, the subcortical white matter area in the PND 5 mice showed significantly greater vulnerability compared with the surrounding striatum and cortex in the same area (arrows in Figure 1D and Figure 3D), which was not seen in PND $9 \mathrm{HI}$ mice (Figure $3 \mathrm{~F}$ and 3G).
In pups subjected to 80 minutes of $\mathrm{HI}, 14 / 16$ (88\%) of the mice were injured and 6/16 (37.5\%) of the mice displayed extensive infarction in the cortex, hippocampus, white matter, and thalamus in the ipsilateral hemisphere (Table 1 and Figure 1F). No injury was observed in the contralateral hemisphere (Figure 1E).

To evaluate the effect of $\mathrm{HI}$ on myelination and graymatter injury, MBP and MAP-2 immunostaining was performed at PND 12 (7 days after $\mathrm{HI}$ ), which is the age when myelin begins to be detectable in mice [34]. After
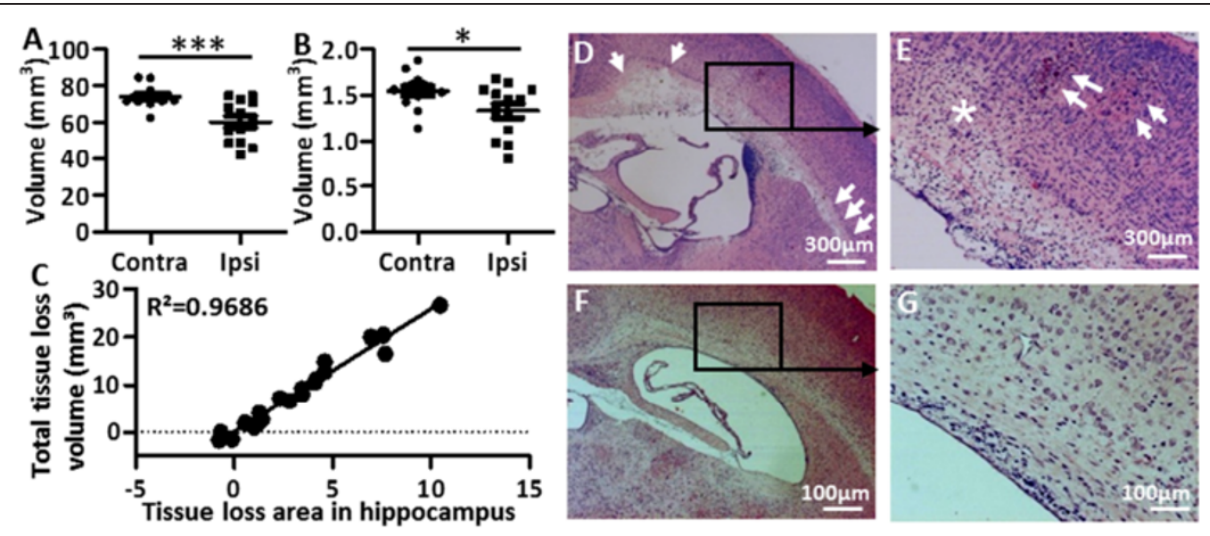

Figure 3 Brain injury after 70-minute hypoxia-ischemia (HI) insult. Dot graphs showing the volume difference between the contralateral and ipsilateral hemispheres in gray matter (A) and white matter (B) at 7 days after 70-minute HI in PND 5 mice $(n=13) .{ }^{*} P<0.05,{ }^{* * *} P<0.001$ using Student's unpaired $t$-test. Data are presented as mean \pm SEM. Abbreviations: Contra: contralateral hemisphere; Ipsi: ipsilateral hemisphere. (C) The simple linear regression analysis shows the linear correlation between the two evaluation methods. (D-G) Representative photomicrographs of H\&E-stained sections show focal injury in the subcortical white matter in the ipsilateral hemispheres at 3 days after HI in PND 5 mice (D and E) but not in PND 9 mice (F and G) with a similar degree of injury. Arrows in (D) show subcortical white-matter injury. Arrows and star in (E) show focal gray-matter injury in the ipsilateral hemisphere of the PND $5 \mathrm{HI}$ mouse brain. 
50 minutes of $\mathrm{HI}$, there was a significant decrease in graymatter volume (Figure 2A) in the ipsilateral hemisphere compared with the contralateral hemisphere. There was no significant difference observed in terms of myelination (Figure 2B) between the two brain hemispheres.

In pups exposed to 70 minutes of $\mathrm{HI}$, both the graymatter volume (Figure 3A) and the white-matter volume (Figure $3 \mathrm{~B}$ ) in the ipsilateral hemisphere were significantly reduced compared with the contralateral hemisphere at 7 days post-HI (PND 12). A simple linear regression analysis comparing the total brain tissue loss (volume) with the tissue loss in one representative brain section (area) from the hippocampus level showed a significant positive linear correlation between the two methods (Figure $3 \mathrm{C}, P<0.001, \mathrm{R}^{2}=0.9686$ ).

At 7 days after HI (PND 12) when myelination was formed and was visible by MBP staining, the subcortical white matter displayed abnormal myelin structure (Figure 4B and 4D) in the ipsilateral hemisphere compared to the normal morphology of the subcortical white matter in the contralateral hemisphere (Figure 4A and 4C). Quantification of MBP-positive immunostaining in the subcortical white matter area demonstrated that the subcortical white matter volume loss in the ipsilateral hemisphere for the 70 minutes $\mathrm{HI}$ group was $14.0 \pm 4.2 \%$, whereas no white matter loss was seen in the 50 minutes $\mathrm{HI}$ group. No gender differences were found for any of the hypoxia durations in this study.

We found that 70 minutes of $\mathrm{HI}$ results in focal diffuse white-matter injury combined with hippocampus injury, small areas of focal cortical injury, and a low frequency of cortical infarction. We concluded, therefore, that 70 minutes is the optimal duration of $\mathrm{HI}$ to induce brain injuries in PND 5 mice, and this model was used in the subsequent characterization of the inflammatory/immune responses after $\mathrm{HI}$ insults.

\section{Increased DAP12 and TREM-2 expression after HI}

Triggering receptors expressed on myeloid cells (TREMs) are innate immune receptors that play an important role in fine-tuning the inflammatory response by altering the innate immune response. DNAX activation protein 12 (DAP12) is a transmembrane signaling adaptor protein that forms a molecular complex with TREM-2. TREM-2 is expressed on the cell membrane of monocyte-derived dendritic cells, osteoclasts, and microglia. Activation of DAP12 and TREM-2 plays an important role in demyelination disease in humans, and this led us to examine the possible role of this pathway in preterm brain injury, which is characterized by extensive white-matter injury.

Brain sections from the hippocampal level were analyzed by immunohistochemistry at 24 hours, 3 days, and 7 days after 70-minute HI at PND 5. TREM-2 expression in the brain was increased in the ipsilateral hemisphere after $\mathrm{HI}$ with maximum expression seen at 24 hours after HI (Figure 5A and 5B). The increased TREM-2 expression at 24 hours after HI was mostly observed in the ipsilateral hippocampus, subcortical white matter, and white matter/thalamus (Figure 5B, 5C, and 5D). TREM2 expression was also found in the meninges and the choroid plexus structure in the lateral and third ventricle (Figure 5E and 5F). The TREM-2 ${ }^{+}$cells were located

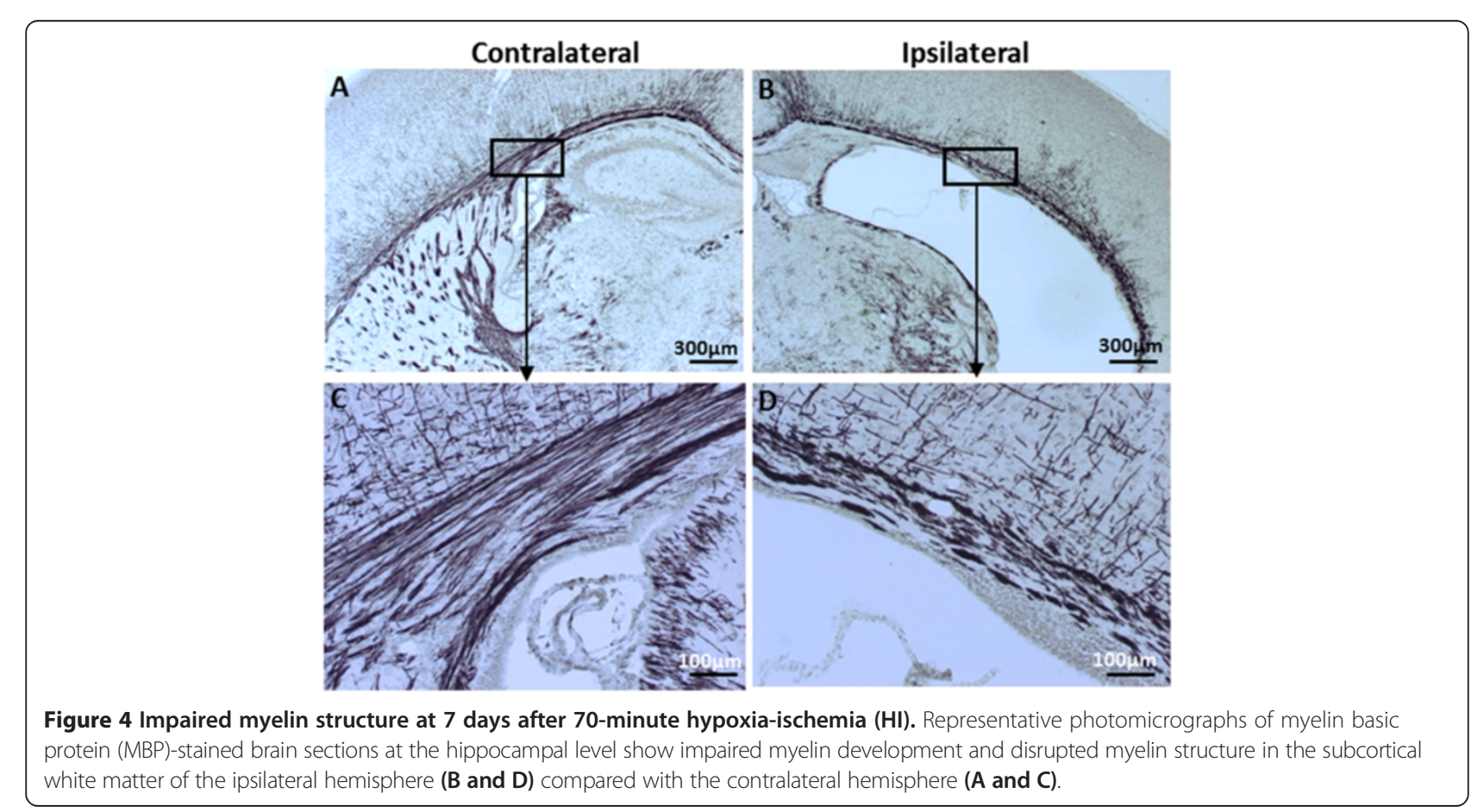



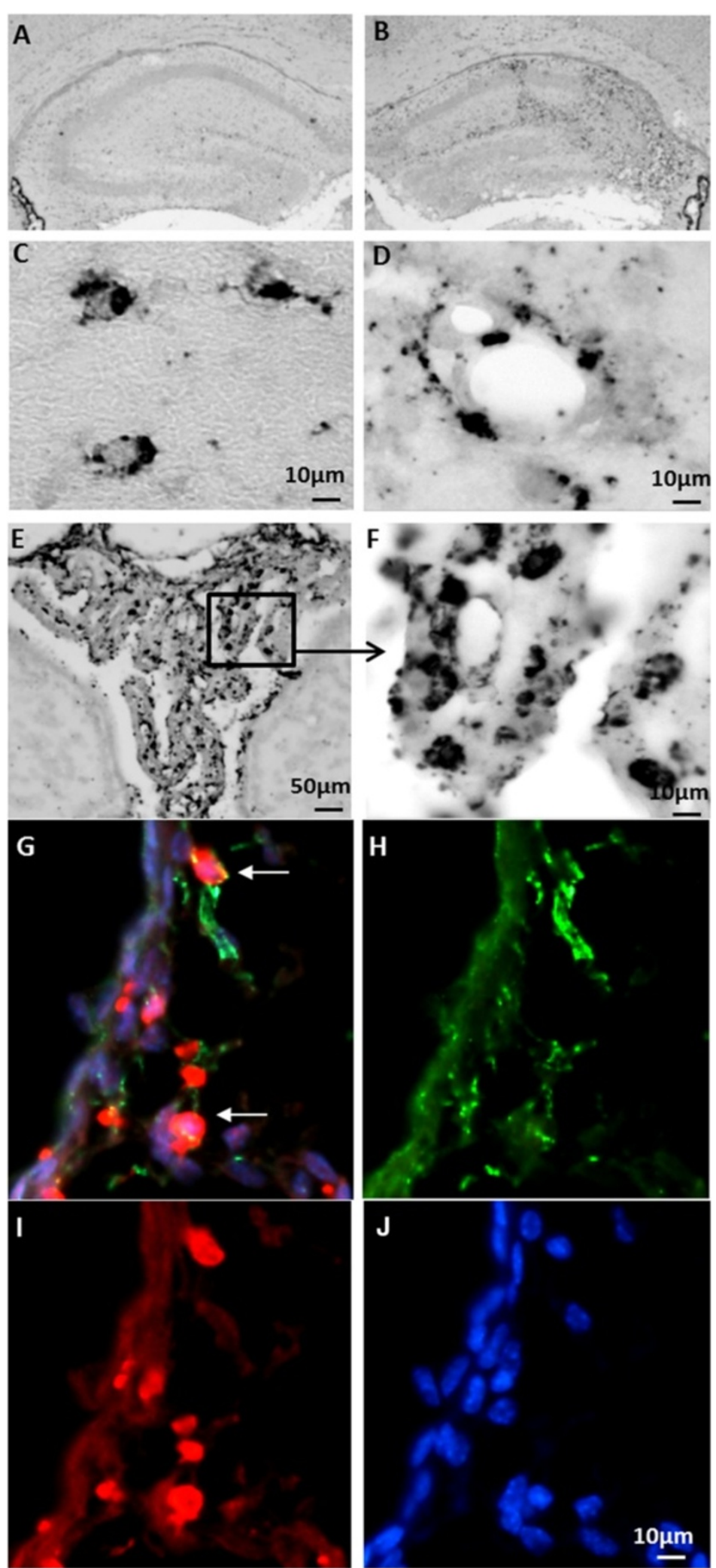

Figure $\mathbf{5}$ (See legend on next page.) 
(See figure on previous page.)

Figure 5 TREM-2 expression after 70-minute hypoxia-ischemia (HI) insult. Representative photomicrographs show TREM- $2^{+}$immunohistochemical staining in the contralateral (A) and ipsilateral (B) hemispheres at 24 hours after HI. (C and D) TREM- $2^{+}$cells in the hippocampus in the brain parenchyma (C) and blood vessels (D). (E) TREM-2 ${ }^{+}$cells in the choroid plexus at 24 hours after HI. (F) A higher magnification of TREM-2 ${ }^{+}$staining. (G-L) TREM-2 staining (H) co-localizes (G, arrows) with microglia marker Iba-1 (I) in the choroid plexus at 24 hours after HI. (J) DAPI nuclear staining.

both within the brain parenchyma (Figure 5C) and along the blood vessels (Figure 5D). The triple fluorescent staining of TREM-2 with microglia marker Iba-1 and DAPI nuclear staining indicated that some TREM- $2^{+}$ cells are microglia (Figure 5G-J). The TREM-2 expression in the lateral ventricles displayed more TREM- $2^{+}$ staining in the ipsilateral lateral ventricle compared to the contralateral ventricle, and the expression was higher in the choroid plexus of the third ventricle at 24 hours after $\mathrm{HI}$ compared to age-matched undamaged controls. However, the TREM- $2^{+}$staining in the meninges did not differ between the two hemispheres.

The DAP12 expression in the brain after 70 minutes HI at PND 5 was evaluated by immunofluorescence staining at 24 hours, 3 days, and 7 days after HI. The expression of DAP12 was found in the injured area in the subcortical white matter area, the hippocampus, the periventricular area, and the meningeal areas in the ipsilateral hemisphere. Triple immunofluorescence staining for DAP12, the microglia marker Iba-1 and DAPI showed that DAP12 and Iba-1 double-positive cells were found in the ipsilateral periventricular area at 24 hours after HI (Figure 6A-6D). Iba- 1 and DAP12 double-positive cells were also detected close to blood vessels in the ipsilateral hippocampus (Figure 6E-6H) and in the meningeal area at three days after HI.

The immune cell response after $\mathrm{HI}$ in PND 5 mice

To examine the possible infiltration of immune cells into the brain after HI, we used immunohistochemical staining with an antibody against CD4. Indeed, the number of $\mathrm{CD} 4^{+}$cells in the brain increased at 24 hours and 7 days after $\mathrm{HI}$ compared with age-matched undamaged control mice (Figure 7A). Most of the $\mathrm{CD} 4^{+}$cells were seen in blood vessels, and only a few were seen in the brain tissue (Figure 7C and 7D). Because it is one of the most important organs of the immune system, spleen weight was measured at 24 hours, 3 days, and 7 days after $\mathrm{HI}$ and in undamaged control mice. A significant increase in spleen weight was seen at 24 hours and 3 days, but not at 7 days, after HI compared to controls (Figure 7B) suggesting that an $\mathrm{HI}$-induced global inflammatory response might increase the trafficking of immune cells, including $\mathrm{CD}_{4}^{+}$ T-cells, into the injured brain during the early phase of inflammation.

\section{Different canonical types of cytokine responses after $\mathrm{HI}$ in PND 5 mice}

To further evaluate the inflammatory/immune response in the HI-induced preterm brain injury model described above, brains were harvested at 6 hours, 24 hours, and 7 days after $\mathrm{HI}$ and from uninjured age-matched control mice. The expression of several cytokine mRNAs was altered in the ipsilateral brain hemisphere after HI (Figure 8) but there were no significant changes in the contralateral brain hemispheres after $\mathrm{HI}$.

We first investigated whether the transcription of immunity-related genes, including those related to CD4+ T-helper (Th) cells, were affected by HI. At six hours after
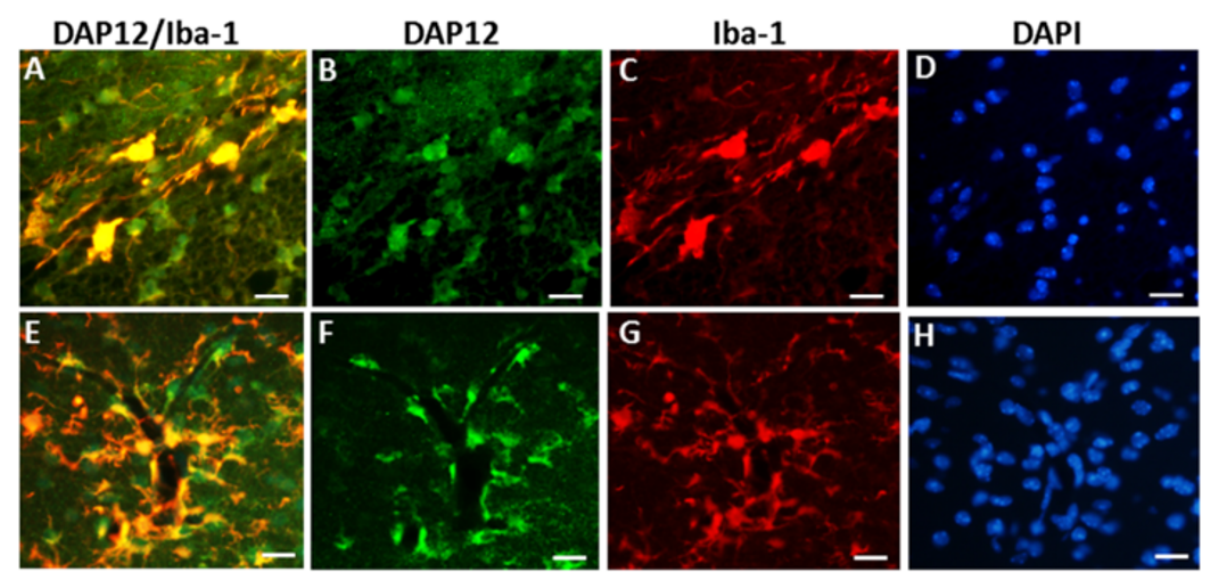

Figure 6 DAP12 expression after a 70-minute hypoxia-ischemia (HI) insult. Representative photomicrographs show expression of DAP12 (green) and its co-localization with the microglia marker Iba-1 (red) after HI. DAP12 and Iba-1 double-positive cells were found in the dentate gyrus (A-D) at 24 hours after $\mathrm{HI}$, and in the proximity of blood vessels in the CA1 area of the hippocampus (E-H) at 3 days after $\mathrm{HI}$. 

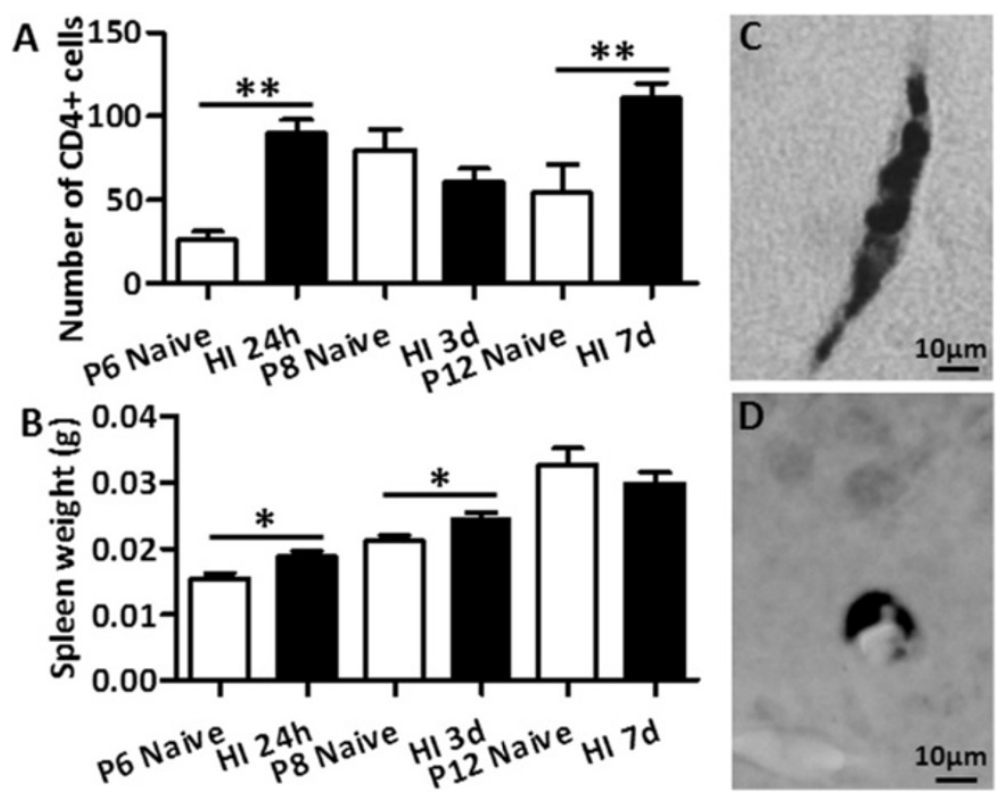

Figure $7 \mathrm{CD}^{+}$T-cells in the mouse brain after hypoxia-ischemia (HI) in postnatal day (PND) 5 mice. The total number of CD4 $4^{+}$cells in blood vessels and in tissue from both of the brain hemispheres from a section at the hippocampus level (A) and spleen weight (B) in uninjured control (Cont) mice versus HI mice at different time points after HI. ${ }^{*} P<0.05$, ${ }^{* *} P<0.01$, ${ }^{* * *} P<0.001$ using Student's unpaired $t$-test. Data are presented as mean \pm SEM. (C and D) Representative immunostainings show $C D 4^{+}$cells in blood vessels in the ipsilateral subcortical white matter (C) and ipsilateral hippocampus CA1 area (D) at seven days post-HI.

$\mathrm{HI}$, there was a significant up-regulation of the mRNAs for the Th type 1 (Th1) cell transcription factor T-bet and the Th1 cell-promoting cytokine IL-12a in the brain (Figure 8). IFN- $\gamma$ - the signature cytokine secreted from Th1 cells - was not detectable in the brain after $\mathrm{HI}$ in PND 5 mice.

The Th2 transcription factor GATA3 was not affected by HI, but the IL- 4 cytokine, which promotes the differentiation of Th2 cells, was significantly down-regulated at 6 hours and 24 hours after HI. IL-13, a cytokine produced mainly by Th2 cells, was significantly up-regulated at 6 hours after HI, but no changes were observed for IL-5 (Figure 8).

For the Th17-type cytokine response, the transcription factor ROR $\gamma$ t was significantly increased at 7 days after HI. The expression of the Th17-promoting cytokine IL-6 was significantly increased at 6 hours and 24 hours after HI. Cytokine IL-22, which is secreted from Th17 cells, was significantly increased at 6 hours after HI. IL-17A was not detected in the brain in the normal control animals at any of the time points analyzed.

For the T-regulatory (Treg) type of response, the expression of the Treg transcription factor Foxp3 was significantly decreased at 6 hours and 24 hours after HI. However, there was no change in levels of the Tregpromoting cytokine TGF- $\beta$ or the Treg-secreted cytokine IL-10.

\section{Discussion}

We have established a novel PND 5 mouse preterm brain injury model to show that both the innate and adaptive immune responses are activated after $\mathrm{HI}$ at this age. This model has allowed us for the first time to examine the responses of different subsets of Th cells in a neonatal HI model, and we found that $\mathrm{HI}$ induced a primarily Th1/Th17-type immune response in the neonatal mice.

Fifty minutes of $\mathrm{HI}$ produced mild injury localized in the white and gray matter, and this degree of injury is similar to that previously reported in PND $6 \mathrm{HI}$ mice [23]. However, only $25 \%$ of the mice were damaged and most of the pups did not display any signs of injury. Furthermore, no significant differences were seen in the white-matter volume between the ipsilateral and contralateral hemispheres, and this limits the usefulness of the 50-minute HI exposure in neuroprotection studies. When the HI duration was extended to 80 minutes, the injury in the ipsilateral hemisphere was very extensive and included widely distributed infarction of the hippocampus, cortex, and thalamus that is rarely seen in preterm infants.

The model using 70 minutes of $\mathrm{HI}$ produced diffuse white-matter injury combined with focal neuronal loss in the cerebral cortex and hippocampus injury (Table 1). Indeed, at 7 days after HI (PND 12), the time when myelination becomes detectable in mice, we found impaired 


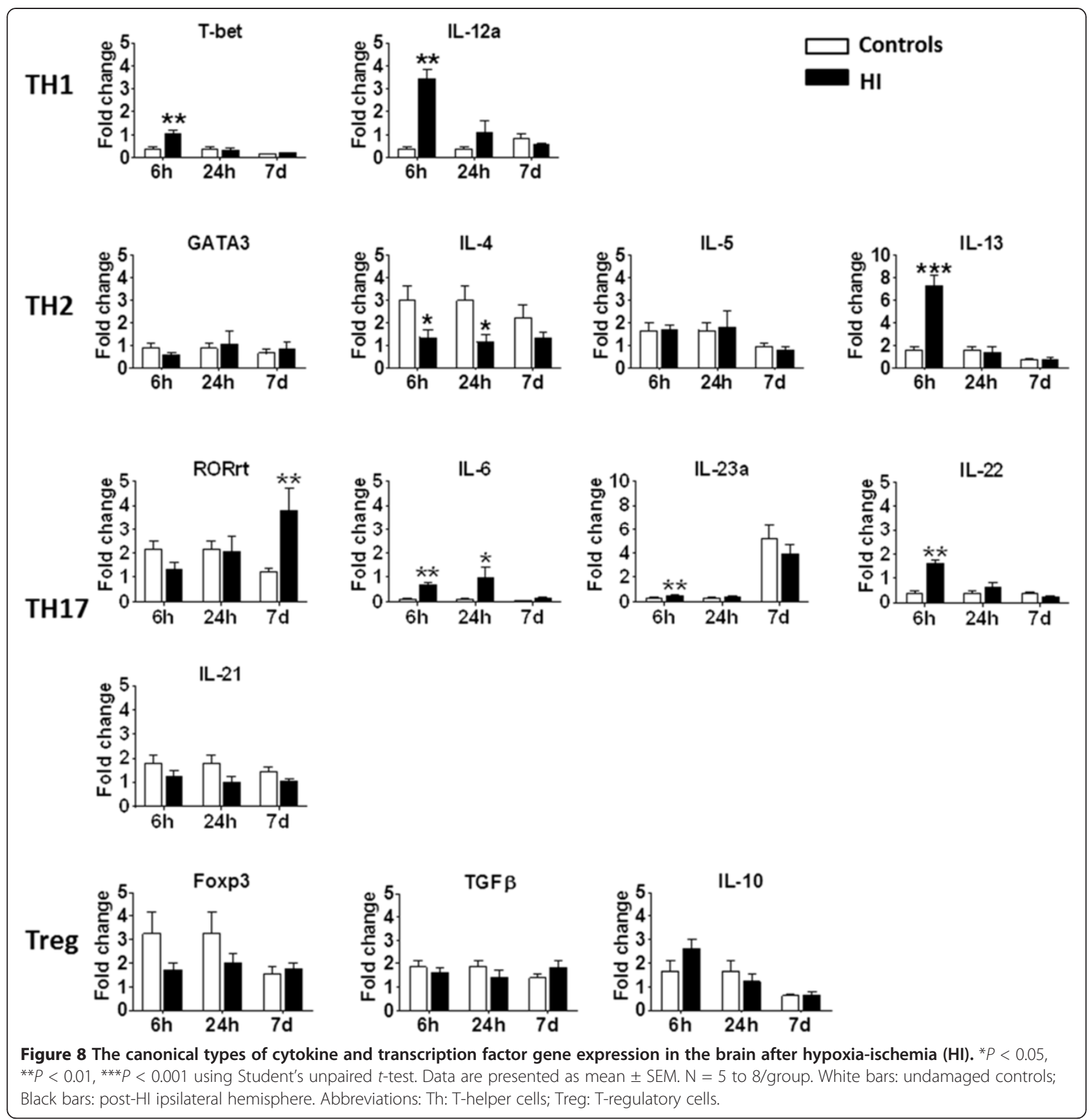

myelination in the subcortical white matter of the ipsilateral hemisphere (Figure 4B and 4D). Seventy minutes of HI significantly reduced both white- and gray-matter volume in $93 \%$ of the pups (Figure 3A and B), and this makes the model reliable and suitable for neuroprotection studies. Interestingly, we found that the degree of white-matter vulnerability after 70 minutes of $\mathrm{HI}$ at PND 5 (Figure 3D and 3E) was more obvious compared to that seen at PND 9 in mice (Figure 3F and 3G). This observation further confirms that PND 5 is within the time window when the white matter in the brain is more vulnerable to injury [35].

TREM-2 is expressed on the cell membrane of monocyte-derived dendritic cells, osteoclasts, and microglia and is associated with the signaling molecule DAP12 [36,37]. DAP12 in turn plays a signal transduction role in dendritic cells and macrophages and is considered to be both pro- and anti-inflammatory [38]. Apart from their function in the inflammatory response, DAP12 and TREM-2 clearly play an important role in white-matter 
disease and oligodendrocyte pathology. Mutations in TREM- 2 and DAP12 cause sclerotic lesions in the white matter of the central nervous system (CNS) in human polycystic lipomembranous osteodysplasia with sclerosing leukoencephalopathy (PLOSL)/Nasu-Hakola disease $[39,40]$ and cause hypomyelinosis in mice [41]. DAP12 ${ }^{+}$ and TREM-2 ${ }^{+}$microglia/macrophages surround myelinating oligodendrocytes at PND 10 [42]. TREM-2 is expressed by microglia in the CNS both during normal development in mice [43] and in experimental autoimmune encephalomyelitis (EAE) - a mouse model of multiple sclerosis (a white-matter disease) [44,45]. Blockage of TREM-2 signaling using an anti-TREM-2 antibody increases the severity and progression of EAE [44].

We found increased expression of TREM-2 and DAP12 in the brain after HI with maximum expression at 24 hours after $\mathrm{HI}$ in the injured areas of the hippocampus and the white matter. DAP12 was co-expressed with microglia in the brain parenchyma, and this agrees with previous findings in the normal neonatal mouse brain [43] and in the rodent model of $\mathrm{HI}$ that is more representative of the type of brain injury seen in fullterm infants [27]. The expression of DAP12 is found not only in injured areas but also in the meninges. Together with the finding that TREM-2 is also expressed in the choroid plexus and along the blood vessels, this indicates that the TREM and DAP12 pathway might serve as a sensor/communicator at the interface between the periphery and the CNS and might participate in the development of white-matter injury in preterm infants.

The accumulation of TREM-2, DAP12, and $\mathrm{CD} 4^{+} \mathrm{T}-$ cells in the meninges and choroid plexus and adherence to blood vessels might also have implications for the status of cerebrovascular reactivity. Similarly, another recent report showed that TREM-2 was expressed by some microglia/macrophages inside and around the blood vessels of the hippocampal fissure in PND 1 mouse brains, and such expression diminished with age [43]. The vasculature of the blood-brain barrier (BBB) protects the CNS from the systemic circulation by restricting entry of unwanted molecules and immune cells into the brain. Reports have shown that TREM-2 knockout mice have reduced invasion of $\mathrm{CD}^{+}$T-cells [46] through yet unknown mechanisms. Together with our finding that TREM-2 is located close to the blood vessels in the choroid plexus, this indicates that TREM-2 might actively participate in the invasion of peripheral T-cells into the brain through the choroid plexus and BBB by either modulating the $\mathrm{BBB}$ permeability in the brain or directly regulating the blood flow.

T-cells have been observed infiltrating the brain in the infarction area in animal models of stroke, and it is now widely accepted that $\mathrm{T}$-cells play a role in both ischemic brain injury (stroke) and white-matter injury (multiple sclerosis) in both adult animal models and humans $[47,48]$. For example, T-cell-deficient mice exhibit significant reductions in infarct volume $[49,50]$ in rodent models of HI brain injury. T-cells and other peripheral immune cells were found to infiltrate into the neonatal rat brain and to remain there for hours to months following HI [51-53].

In this study, we found that there were low, yet significantly increased, numbers of $\mathrm{CD} 4^{+}$cells in the brain after $\mathrm{HI}$ at PND 5 and that this was accompanied by changes in spleen weight, one of the most important organs in the immune system. At the time points examined in the present study, which are all relatively early for the adaptive immune response, the $\mathrm{CD} 4^{+} \mathrm{T}$-cells are mostly located adhered to the blood vessels in the brain instead of in the brain parenchyma. This might well indicate that $\mathrm{CD} 4^{+}$cells are beginning to infiltrate into the brain at a relatively early stage in the adaptive immune response in addition to other cell types that are also involved in the early immune response in the brain.

Mammalian immune responses are often grouped into type 1 and type 2 responses [54]. These responses differ broadly in their mechanisms of induction as well as their innate cell types, cytokines, effector molecules, and Th types. The classical type 1 and type 2 responses are mediated by TCR $\alpha \beta C D 4^{+}$Th cells and are thus generally referred to as Th1 and Th2 responses, respectively. It is now clear that many innate cell types such as $\gamma \delta$ T-cells and innate lymphoid cells (ILCs) broadly parallel the known $\mathrm{CD}^{+}{ }^{+} \mathrm{Th}$ cell subsets in terms of their signature cytokine secretion profiles. An overlapping series of transcription factors is also used to drive the differentiation of the various ILC and Th cell subsets. The results of our experiments show that HI leads to an imbalance between Th1/Th17-type responses and Th2/Treg-type responses, and these differences might be due to the recruitment and proliferation of different innate-type immune cells.

Type 1 immune responses are usually pro-inflammatory and are mediated by the type 1 cytokines such as IFN- $\gamma$, TNF- $\alpha$, IL-6, and IL-17 [55]. In contrast, type 2 responses have immune-modulating functions and mediate allergic inflammatory diseases such as asthma, allergic rhinitis, and atopic dermatitis. Th2 cells regulate type 2 responses through the secretion of various type 2 cytokines, including IL-4, IL-5, IL-9, and IL-13. For many years, neonates have been considered to be immune deficient. It is now clear, however, that the newborn is capable of raising an immune response. Neonatal mice that have primary immune responses to certain foreign antigens normally mount Th2-type-dominant secondary responses when re-exposed to the same antigens. However, under certain pathogenic infections or after immunization with certain adjuvants that promote strong Th1-cell responses, such as 
DNA vaccines or oligonucleotides containing CPG motifs, neonates develop Th1-type responses that often induce the onset of diseases [54,56,57]. In HI-induced brain injury in neonatal mice, we observed an increased expression of Th1/Th17-related transcription factors that may reflect a dominant Th1-type response that could contribute to the brain injury. Indeed, high expression of Th1 and Th17type cytokines has been found in PVL patients [58-60], and inhibition of Th17-type cytokines reduces brain injury in a neonatal mouse model [61]. Moreover, Th17 lymphocytes traffic to the CNS [62] and participate in the pathogenesis of CNS inflammatory demyelination disease [63]. These indicate that different types of immune responses might play different roles in preterm brain injury.

In this study, we examined different types of immune responses by examining the stimulatory cytokines that are present in the microenvironment during activation, transcription factors that prime naive precursor cells for differentiation, and the signature cytokine profiles for each type of response. We observed significantly increased levels of Th1-related (T-bet, IL-12a) and Th17-related (ROR $\gamma$ t, IL6, IL-23, and IL-22) transcription factors and cytokines after HI, and most Th2/Treg-related transcription factors and cytokines were either decreased (IL-4) or unchanged (GATA3, IL-5, Foxp3, TGF $\beta$, and IL-10). Notably, the signature cytokine for Th17-related response (IL-17A) was not detectable in the neonatal mouse brain in the current study. We carefully analyzed the IL-17A expression in normal neonatal mice, but could not detect any mRNA under our experimental conditions. However, analysis of IL-17A expression in the present study focused on the early time points within 7 days post-HI when the adaptive immune responses are not initiated, and the early Th1/ Th17-type response in the brain after $\mathrm{HI}$ might be due to innate-type cell types, for example, $\gamma \delta$ T-cells and ILCs. Possibly, IL-17A could be expressed at later time points after $\mathrm{HI}$ when massive infiltration of T-cells into the CNS starts, since unlike its other analogs (that is, IL-17F), IL-17A is produced mainly in T-cells [64]. For the Th2type response, we did find significantly increased levels of the Th2-type cytokine IL-13 in the brain at 6 hours after HI. IL-13 is a mediator of allergic inflammation and disease, and in the brain IL-13 has been found to induce oxidative stress and contribute to the death of activated microglia $[65,66]$. In general, it seems that the physiological Th2/Treg-type bias is lost in preterm brain injury after $\mathrm{HI}$ in mice and that the balance is instead skewed towards a type 1 (Th1/Th17) immune response (Figure 8).

Altogether, these results indicate that HI triggers a robust immune response in the brain that is characterized by an imbalance between Th1/Th17- and Th2/Treg-type responses. This imbalance occurs early in the immune response and is probably caused by an innate type of response as indicated by the increased yet low number of $\mathrm{CD}^{+}$cells mostly located in the blood vessels.

\section{Conclusions}

Cerebral palsy is the most common severe neurological disability in children worldwide and is a heavy burden on those afflicted, their families, and society. Preterm brain injury is a major cause of cerebral palsy and there are currently no neuroprotective therapies available for premature infants. Inflammation plays a critical role in the development of preterm brain injury, and T-cells have been suggested to play essential roles in the response to ischemic brain injury $[47,48,51,52]$. Therefore, targeting the inflammation-specific immune cell population/pathways $[9,67,68]$ might represent a new hope for the prevention and treatment of preterm brain injury. In the present study, we have established a reproducible PND 5 mouse model of HI-induced preterm brain injury, and we have further characterized the innate and adaptive immune responses and found the involvement of a Th1/Th17-type immune response after $\mathrm{HI}$-induced preterm brain injury in the established model. This model will provide a powerful tool to study preterm brain injury mechanisms and to investigate possible neuroprotectants with the goal of discovering treatment strategies for preterm brain injury. The immune response observed in this model will provide a solid foundation for continued studies of the contribution of the neonatal immune system to preterm brain injury and provide evidence for neuroprotection by targeting specific inflammatory cascades after preterm brain injury.

\section{Abbreviations}

BBB: blood-brain barrier; BTLA: B- and T-lymphocyte attenuator; CNS: central nervous system; DAB: 3,3'-diaminobenzidine; DAPI: 4,6-diamidino-2phenylindole; DAP12: DNAX activation protein of $12 \mathrm{kDa}$; EAE: experimental autoimmune encephalomyelitis; Foxp3: forkhead box P3; GATA3: GATA binding protein 3; H\&E: hematoxylin and eosin; HI: hypoxia-ischemia; IFN: interferon; IL: interleukin; ILCs: innate lymphoid cells; MAP-2: microtubule-associated protein 2; MBP: myelin basic protein; OL: oligodendrocyte; PCR: polymerase chain reaction; PLOSL: polycystic lipomembranous osteodysplasia with sclerosing leukoencephalopathy; PND: postnatal day; preOLs: premyelinating oligodendrocytes; PVL: periventricular leukomalacia; RORyt: RAR-related orphan receptor gamma; TGF- $\beta$ : transforming growth factor beta; Th: T-helper cell; TNF: tumor necrosis factor; Treg: T-regulatory; TREM-2: triggering receptor expressed on myeloid cells 2 .

\section{Competing interests}

The authors declare that they have no competing interests.

\section{Authors' contributions}

$A A, D B, L D, X Z$, and $L Q$ performed the experiments. AA, DB, JL, CZ, XW, and SC analyzed the data. XW conceived and designed the experiments. XW and AA wrote the paper. JL, CZ, SC, HC, HH, and CM participated in the study design, data interpretation, and critically revised the manuscript for important intellectual content. All authors read and approved the final manuscript.

\section{Acknowledgements}

This work was supported by the Swedish Medical Research Council (VR 20082286 and VR 2013-2475 to XW, VR 2012-3500 to HH, and VR 2012-2992 to CM), the Bill \& Melinda Gates Foundation Grand Challenge Explorations and Global Health (OPP1036135 to XW), Swedish governmental grants to researchers in the public health service (ALFGBG-367051 to XW, ALFGBG-2863 
to $\mathrm{HH}$, and ALFGBG-142881 to CM), VINNMER-Marie Curie international qualification (VINNOVA, 2011-03458 to XW), Wilhelm and Martina Lundgren (37/2013 to XW and 35/2012 to AM), Wilhelm and Martina Lundgren Foundation $(\mathrm{HH})$, the Åhlén Foundation $(\mathrm{HH}, \mathrm{CM})$, Wellcome Trust (WT094823 HH), the Frimurare Barnhus Foundation (HH), the Byggmästare Olle Engqvist Foundation ( $\mathrm{HH}, \mathrm{CM}$ ), the Leducq Foundation (DSRR-P34404 to $\mathrm{CM}$ and $\mathrm{HH}$ ), and the Swedish Brain Foundation (FO2013-0095 to CM, 2013-0035 HH).

\section{Author details}

'Perinatal Center, Department of Neuroscience and Physiology, Sahlgrenska Academy, University of Gothenburg, Box 432, SE-405 30 Gothenburg, Sweden. ${ }^{2}$ Department of Pediatrics, The Third Affiliated Hospital of Zhengzhou University, Zhengzhou, China. ${ }^{3}$ Department of Cancer Immunology and AIDS, Dana-Farber Cancer Institute, Harvard Medical School, Boston, MA, USA. ${ }^{4}$ Department of Microbiology and Immunobiology, Division of Immunology, Harvard Medical School, Boston, MA, USA. ${ }^{5}$ Department of Pediatrics, Song Jiang Central Hospital, Shanghai, China. ${ }^{6}$ Center for Brain Repair and Rehabilitation, Department of Neuroscience and Physiology, Sahlgrenska Academy, University of Gothenburg, Gothenburg, Sweden. 'Department of Microbiology and Immunology, Institute of Biomedicine, Sahlgrenska Academy, University of Gothenburg, Gothenburg, Sweden. ${ }^{8}$ Department of Clinical Sciences, East Hospital, 41685 Gothenburg, Sweden. ${ }^{9}$ Centre for the Developing Brain, Department of Perinatal Imaging and Health, King's College London, St. Thomas' Hospital, London SE1 7EH UK.

Received: 3 June 2014 Accepted: 14 August 2014

Published online: 05 September 2014

\section{References}

1. Pierson CR, Folkerth RD, Billiards SS, Trachtenberg FL, Drinkwater ME, Volpe JJ, Kinney HC: Gray matter injury associated with periventricular leukomalacia in the premature infant. Acta Neuropathol 2007, 114:619-631.

2. Leviton A, Gressens P: Neuronal damage accompanies perinatal whitematter damage. Trends Neurosci 2007, 30:473-478.

3. Inder TE, Huppi PS, Warfield S, Kikinis R, Zientara GP, Barnes PD, Jolesz F, Volpe JJ: Periventricular white matter injury in the premature infant is followed by reduced cerebral cortical gray matter volume at term. Ann Neurol 1999, 46:755-760

4. Back SA, Miller SP: Brain injury in premature neonates: a primary cerebral dysmaturation disorder? Ann Neurol 2014, 75:469-486

5. Fleiss $B$, Gressens P: Tertiary mechanisms of brain damage: a new hope for treatment of cerebral palsy? Lancet Neurol 2012, 11:556-566.

6. Ferriero DM: Neonatal brain injury. N Engl J Med 2004, 351:1985-1995.

7. Volpe J: Brain injury in premature infants: a complex amalgam of destructive and developmental disturbances. Lancet Neurol 2009, 8:110-124.

8. Dammann O, Leviton A: Maternal intrauterine infection, cytokines, and brain damage in the preterm newborn. Pediatr Res 1997, 42:1-8.

9. Hagberg H, Gressens P, Mallard C: Inflammation during fetal and neonatal life: implications for neurologic and neuropsychiatric disease in children and adults. Ann Neurol 2012, 71:444-457.

10. Takashima S, Tanaka K: Development of cerebrovascular architecture and its relationship to periventricular leukomalacia. Arch Neurol 1978, 35:11-16.

11. Nakamura $Y$, Okudera T, Hashimoto T: Vascular architecture in white matter of neonates: its relationship to periventricular leukomalacia. I Neuropathol Exp Neurol 1994, 53:582-589.

12. Pryds O: Control of cerebral circulation in the high-risk neonate. Ann Neurol 1991, 30:321-329.

13. Rice JE 3rd, Vannucci RC, Brierley JB: The influence of immaturity on hypoxic-ischemic brain damage in the rat. Ann Neurol 1981, 9:131-141.

14. Vannucci SJ, Hagberg H: Hypoxia-ischemia in the immature brain. J Exp Biol 2004, 207:3149-3154.

15. Vannucci RC, Vannucci SJ: Perinatal hypoxic-ischemic brain damage: evolution of an animal model. Dev Neurosci 2005, 27:81-86.

16. Zhu C, Wang X, Xu F, Bahr BA, Shibata M, Uchiyama Y, Hagberg H, Blomgren K. The influence of age on apoptotic and other mechanisms of cell death after cerebral hypoxia-ischemia. Cell Death Differ 2005, 12:162-176.

17. Hagberg H, Bona E, Gilland E, Puka-Sundvall M: Hypoxia-ischaemia model in the 7-day-old rat: possibilities and shortcomings. Acta Paediatr Supp/ 1997, 422:85-88.
18. Vannucci RC, Connor JR, Mauger DT, Palmer C, Smith MB, Towfighi J, Vannucci SJ: Rat model of perinatal hypoxic-ischemic brain damage. J Neurosci Res 1999, 55:158-163.

19. Vannucci RC, Vannucci SJ: A model of perinatal hypoxic-ischemic brain damage. Ann N Y Acad Sci 1997, 835:234-249.

20. Northington FJ: Brief update on animal models of hypoxic-ischemic encephalopathy and neonatal stroke. ILAR J 2006, 47:32-38.

21. Sheldon RA, Sedik C, Ferriero DM: Strain-related brain injury in neonatal mice subjected to hypoxia-ischemia. Brain Res 1998, 810:114-122.

22. Sizonenko SV, Sirimanne E, Mayall Y, Gluckman PD, Inder T, Williams C: Selective cortical alteration after hypoxic-ischemic injury in the very immature rat brain. Pediatr Res 2003, 54:263-269.

23. Shen Y, Plane JM, Deng W: Mouse models of periventricular leukomalacia. $J$ Vis Exp 2010, 39:1965.

24. Follett PL, Deng W, Dai W, Talos DM, Massillon L, Rosenberg PA, Volpe JJ, Jensen FE: Glutamate receptor-mediated oligodendrocyte toxicity in periventricular leukomalacia: a protective role for topiramate. J Neurosci 2004, 24:4412-4420.

25. Back SA, Luo NL, Borenstein NS, Levine JM, Volpe JJ, Kinney HC: Late oligodendrocyte progenitors coincide with the developmental window of vulnerability for human perinatal white matter injury. J Neurosci 2001, 21:1302-1312

26. Craig A, Ling Luo N, Beardsley DJ, Wingate-Pearse N, Walker DW, Hohimer AR, Back SA: Quantitative analysis of perinatal rodent oligodendrocyte lineage progression and its correlation with human. Exp Neurol 2003, 181:231-240.

27. Hedtjarn M, Mallard C, Hagberg H: Inflammatory gene profiling in the developing mouse brain after hypoxia-ischemia. J Cereb Blood Flow Metab 2004, 24:1333-1351.

28. Saliba E, Henrot A: Inflammatory mediators and neonatal brain damage. Biol Neonate 2001, 79:224-227.

29. Bona C: Neonatal Immunity. Totowa, New Jersey: Humana Press; 2005.

30. Zhu C, Qiu L, Wang X, Xu F, Nilsson M, Cooper-Kuhn C, Kuhn HG, Blomgren K: Age-dependent regenerative responses in the striatum and cortex after hypoxia-ischemia. J Cereb Blood Flow Metab 2009, 29:342-354.

31. Wang X, Stridh L, Li W, Dean J, Elmgren A, Gan L, Eriksson K, Hagberg H, Mallard C: Lipopolysaccharide sensitizes neonatal hypoxic-ischemic brain injury in a MyD88-dependent manner. J Immunol 2009, 183:7471-7477.

32. Wang $X$, Hagberg H, Zhu C, Jacobsson B, Mallard C: Effects of intrauterine inflammation on the developing mouse brain. Brain Res 2007, 1144:180-185.

33. Du X, Fleiss B, Li H, D'Angelo B, Sun Y, Zhu C, Hagberg H, Levy O, Mallard C, Wang $X$ : Systemic stimulation of TLR2 impairs neonatal mouse brain development. PLOS ONE 2011, 6:e19583.

34. Vincze A, Mazlo M, Seress L, Komoly S, Abraham H: A correlative light and electron microscopic study of postnatal myelination in the murine corpus callosum. Int J Dev Neurosci 2008, 26:575-584.

35. Back SA, Riddle A, McClure MM: Maturation-dependent vulnerability of perinatal white matter in premature birth. Stroke 2007, 38:724-730.

36. Retzlaff M, Hagn F, Mitschke L, Hessling M, Gugel F, Kessler H, Richter K, Buchner J: Asymmetric activation of the hsp90 dimer by its cochaperone aha1. Mol Cell 2010, 37:344-354.

37. Klesney-Tait J, Turnbull IR, Colonna M: The TREM receptor family and signal integration. Nat Immunol 2006, 7:1266-1273.

38. Bassett JD, Yang TC, Bernard D, Millar JB, Swift SL, McGray AJ, VanSeggelen $H$, Boudreau JE, Finn JD, Parsons R, Evelegh C, Damjanovic D, Grinshtein N, Divangahi M, Zhang L, Xing Z, Wan Y, Bramson JL: CD8+ T-cell expansion and maintenance after recombinant adenovirus immunization rely upon cooperation between hematopoietic and nonhematopoietic antigenpresenting cells. Blood 2011, 117:1146-1155.

39. Lehnardt S, Henneke P, Lien E, Kasper DL, Volpe JJ, Bechmann I, Nitsch R Weber JR, Golenbock DT, Vartanian T: A mechanism for neurodegeneration induced by group $B$ streptococci through activation of the TLR2/MyD88 pathway in microglia. J Immunol 2006, 177:583-592.

40. Tanaka J: Nasu-Hakola disease: a review of its leukoencephalopathic and membranolipodystrophic features. Neuropathology 2000, 20(Suppl):S25-S29.

41. Kaifu T, Nakahara J, Inui M, Mishima K, Momiyama T, Kaji M, Sugahara A, Koito H, Ujike-Asai A, Nakamura A, Kanazawa K, Tan-Takeuchi K, Iwasaki K, Yokoyama WM, Kudo A, Fujiwara M, Asou H, Takai T: Osteopetrosis and thalamic hypomyelinosis with synaptic degeneration in DAP12-deficient mice. J Clin Invest 2003, 111:323-332. 
42. Thrash JC, Torbett BE, Carson MJ: Developmental regulation of TREM2 and DAP12 expression in the murine CNS: implications for Nasu-Hakola disease. Neurochem Res 2009, 34:38-45.

43. Chertoff M, Shrivastava K, Gonzalez B, Acarin L, Gimenez-Llort L: Differential modulation of TREM2 protein during postnatal brain development in mice. PLOS ONE 2013, 8:e72083.

44. Ford JW, MCVicar DW: TREM and TREM-type receptors in inflammation and disease. Curr Opin Immunol 2009, 21:38-46.

45. Piccio L, Buonsanti C, Mariani M, Cella M, Gilfillan S, Cross AH, Colonna M, Panina-Bordignon P: Blockade of TREM-2 exacerbates experimental autoimmune encephalomyelitis. Eur J Immunol 2007, 37:1290-1301.

46. Sieber MW, Jaenisch N, Brehm M, Guenther M, Linnartz-Gerlach B, Neumann $\mathrm{H}$, Witte OW, Frahm C: Attenuated inflammatory response in triggering receptor expressed on myeloid cells 2 (TREM2) knock-out mice following stroke. PLOS ONE 2013, 8:e52982.

47. ladecola C, Anrather J: The immunology of stroke: from mechanisms to translation. Nat Med 2011, 17:796-808.

48. Shichita T, Sugiyama Y, Ooboshi H, Sugimori H, Nakagawa R, Takada I, Iwaki T, Okada Y, lida M, Cua DJ, Iwakura Y, Yoshimura A: Pivotal role of cerebral interleukin-17-producing gammadeltaT cells in the delayed phase of ischemic brain injury. Nat Med 2009, 15:946-950.

49. Yilmaz G, Arumugam TV, Stokes KY, Granger DN: Role of T lymphocytes and interferon-gamma in ischemic stroke. Circulation 2006, 113:2105-2112.

50. Hurn PD, Subramanian S, Parker SM, Afentoulis ME, Kaler LJ, Vandenbark AA, Offner $\mathrm{H}$ : T- and B-cell-deficient mice with experimental stroke have reduced lesion size and inflammation. J Cereb Blood Flow Metab 2007, 27:1798-1805

51. Winerdal M, Winerdal ME, Kinn J, Urmaliya V, Winqvist O, Aden U: Long lasting local and systemic inflammation after cerebral hypoxic ischemia in newborn mice. PLOS ONE 2012, 7:e36422.

52. Bona $E$, Andersson AL, Blomgren K, Gilland E, Puka-Sundvall M, Gustafson K, Hagberg $\mathrm{H}$ : Chemokine and inflammatory cell response to hypoxiaischemia in immature rats. Pediatr Res 1999, 45:500-509.

53. Benjelloun N, Renolleau S, Represa A, Ben-Ari Y, Charriaut-Marlangue C: Inflammatory responses in the cerebral cortex after ischemia in the P7 neonatal rat. Stroke 1999, 30:1916-1923.

54. Adkins B, Leclerc C, Marshall-Clarke S: Neonatal adaptive immunity comes of age. Nat Rev Immunol 2004, 4:553-564.

55. Spits H, Di Santo JP: The expanding family of innate lymphoid cells: regulators and effectors of immunity and tissue remodeling. Nat Immunol 2011, 12:21-27.

56. PrabhuDas M, Adkins B, Gans H, King C, Levy O, Ramilo O, Siegrist CA: Challenges in infant immunity: implications for responses to infection and vaccines. Nat Immunol 2011, 12:189-194.

57. Zaghouani $\mathrm{H}$, Hoeman CM, Adkins B: Neonatal immunity: faulty T-helpers and the shortcomings of dendritic cells. Trends Immuno/ 2009, 30:585-591.

58. Folkerth RD, Keefe RJ, Haynes RL, Trachtenberg FL, Volpe JJ, Kinney HC: Interferon-gamma expression in periventricular leukomalacia in the human brain. Brain Pathol 2004, 14:265-274

59. Yoon BH, Romero R, Kim CJ, Koo JN, Choe G, Syn HC, Chi JG: High expression of tumor necrosis factor-alpha and interleukin- 6 in periventricular leukomalacia. Am J Obstet Gynecol 1997, 177:406-411.

60. Ellison VJ, Mocatta TJ, Winterbourn CC, Darlow BA, Volpe JJ, Inder TE: The relationship of CSF and plasma cytokine levels to cerebral white matter injury in the premature newborn. Pediatr Res 2005, 57:282-286.

61. Kendall GS, Hristova M, Horn S, Dafou D, Acosta-Saltos A, Almolda B, Zbarsky V, Rumajogee P, Heuer H, Castellano B, Pfeffer K, Nedospasov SA, Peebles DM, Raivich G: TNF gene cluster deletion abolishes lipopolysaccharidemediated sensitization of the neonatal brain to hypoxic ischemic insult. Lab Invest 2011, 91:328-341.

62. Rothhammer V, Heink S, Petermann F, Srivastava R, Claussen MC, Hemmer $B$, Korn T: Th17 lymphocytes traffic to the central nervous system independently of alpha4 integrin expression during EAE. J Exp Med 2011, 208:2465-2476

63. Rostami A, Ciric B: Role of Th17 cells in the pathogenesis of CNS inflammatory demyelination. J Neurol Sci 2013, 333:76-87.

64. Ishigame H, Kakuta S, Nagai T, Kadoki M, Nambu A, Komiyama Y, Fujikado N, Tanahashi Y, Akitsu A, Kotaki H, Sudo K, Nakae S, Sasakawa C, Iwakura Y: Differential roles of interleukin-17A and $-17 \mathrm{~F}$ in host defense against mucoepithelial bacterial infection and allergic responses. Immunity 2009, 30:108-119.
65. Yang MS, Park EJ, Sohn S, Kwon HJ, Shin WH, Pyo HK, Jin B, Choi KS, Jou I, Joe EH: Interleukin-13 and -4 induce death of activated microglia. Glia 2002, 38:273-280.

66. Won SY, Kim SR, Maeng S, Jin BK: Interleukin-13/Interleukin-4-induced oxidative stress contributes to death of prothrombinkringle-2 (pKr-2)activated microglia. J Neuroimmunol 2013, 265:36-42.

67. Fathali N, Ostrowski RP, Lekic T, Jadhav V, Tong W, Tang J, Zhang JH: Cyclooxygenase-2 inhibition provides lasting protection against neonatal hypoxic-ischemic brain injury. Crit Care Med 2010, 38:572-578.

68. Strunk T, Inder T, Wang X, Burgner D, Mallard C, Levy O: Infection-induced inflammation and cerebral injury in preterm infants. Lancet Infect Dis 2014, 14:751-762.

\section{doi:10.1186/s12974-014-0153-z}

Cite this article as: Albertsson et al:: The immune response after hypoxia-ischemia in a mouse model of preterm brain injury. Journal of Neuroinflammation 2014 11:153.

\section{Submit your next manuscript to BioMed Central and take full advantage of:}

- Convenient online submission

- Thorough peer review

- No space constraints or color figure charges

- Immediate publication on acceptance

- Inclusion in PubMed, CAS, Scopus and Google Scholar

- Research which is freely available for redistribution 